\title{
latrogenic biliary injury in a patient with Roux-en-Y hepaticojejunostomy: stenting repair with single- balloon enteroscopy-assisted ERCP
}

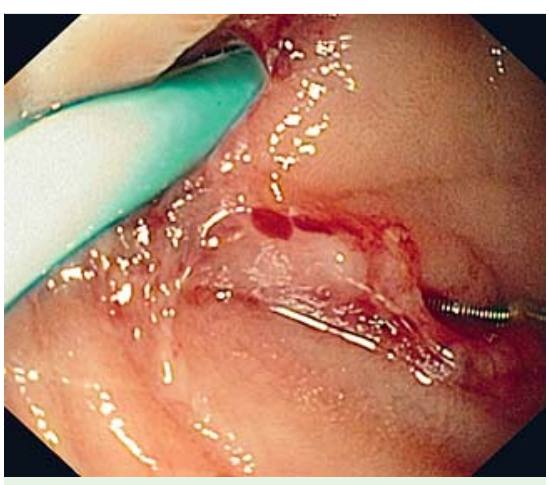

Fig. 1 Enteroscopic view of the biliodigestive anastomosis, in a 64-year-old woman with a history of Roux-en-Y hepaticojejunostomy, performed because of iatrogenic bile duct injury during cholecystectomy. She had recurrent episodes of cholangitis because of stricture of the hepaticojejunostomy and so dilation and plastic stenting of the left bile duct was done, but there was accidental injury to the right biliary duct. The percutaneously placed left duct stent and guidewire can be seen. The guidewire is exiting the right duct.

A 64-year-old woman who had previously undergone a Roux-en-Y hepaticojejunostomy because of iatrogenic bile duct injury during cholecystectomy, presented recurrent episodes of cholangitis due to a stenosis of the hepaticojejunostomy. A percutaneous transhepatic cholangiography with biliary dilation and plastic stenting of the biliodigestive anastomosis was performed. After a successful left duct approach, accidental laceration of the right biliary duct occurred. Percutaneous stenting was impossible because the guidewire repeatedly looped through the laceration. The patient was referred for single-balloon enteroscopy (SBE)-assisted endoscopic retrograde cholangiopancreatography (ERCP). The enteroscope (SIF-Q180; Olympus Medical Systems, Tokyo, Japan) was advanced into the jejunum and the afferent limb was intubated. The hepaticojejunostomy was identified, with visualization of the left duct plastic stent and the guidewire that had been placed percutaneously ( Fig.1). Cholangiography confirmed a right duct biliary leak ( $\bullet$ Fig.2), and guidewire looping ( $\bullet$ Fig.3) near the biliodigestive anastomosis. In a combined endoscopic and percutaneous rendezvous

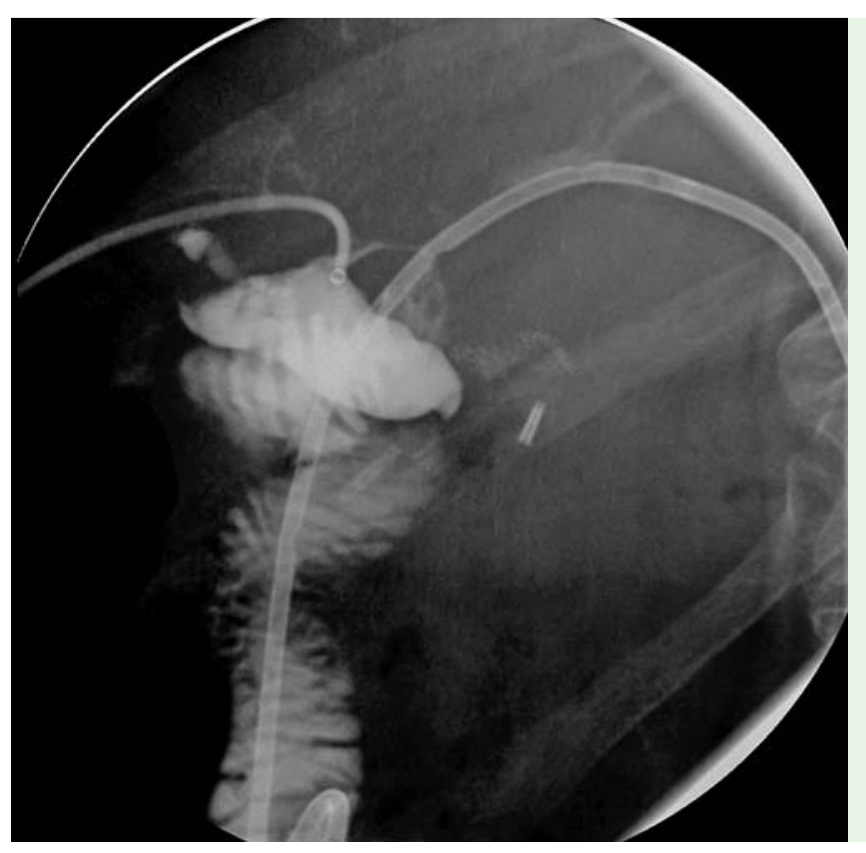

Fig. 2 Contrast injection into the biliary system showing biliary leakage in the right duct, near the biliodigestive anastomosis.

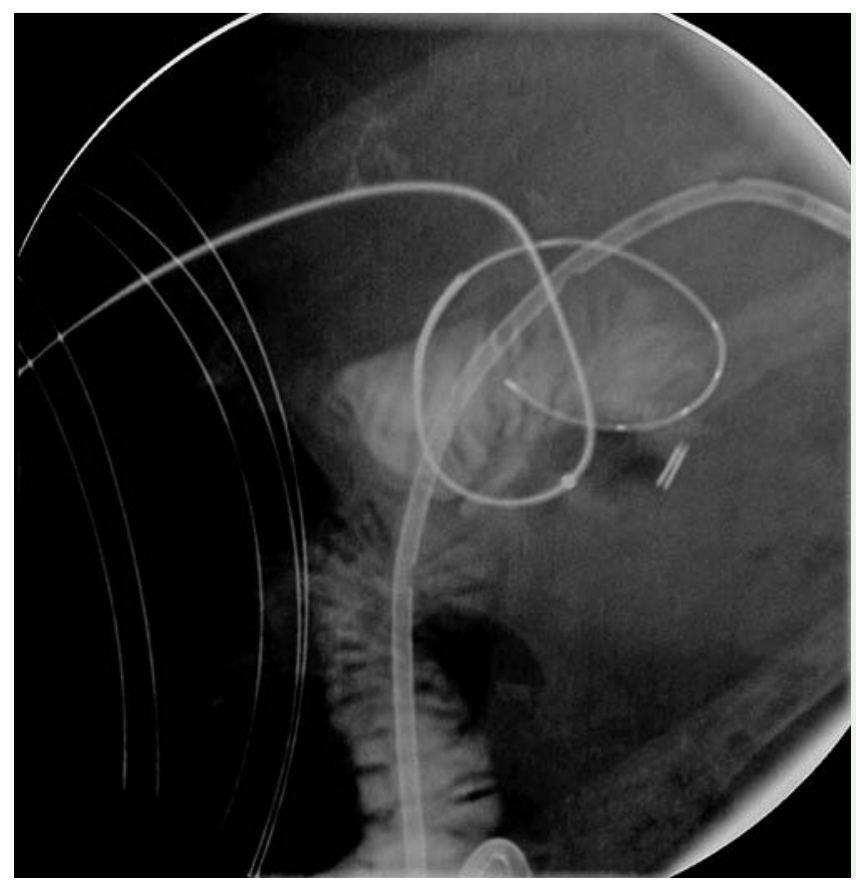

Fig. 3 Fluoroscopic view showing the guidewire looping through the laceration in the right biliary duct.

procedure, the guidewire was straightened and a 7-Fr plastic stent $(3 \mathrm{~cm}$; Olympus, Japan) was placed endoscopically ( Fig.4) through the hepaticojejunostomy, excluding the biliary duct laceration $(\bullet$ Fig. 4 and $\bullet$ Fig. 5).

SBE-ERCP was subsequently repeated, with biliary stent removal through the overtube. Cholangiography revealed no biliary leak or anastomotic stricture (๑ Fig.6).

Iatrogenic biliary duct injuries are serious conditions, for which endoscopic stenting treatment has gained increasing potential. For patients with complex post-surgical anatomy, SBE for ERCP is a safe and 


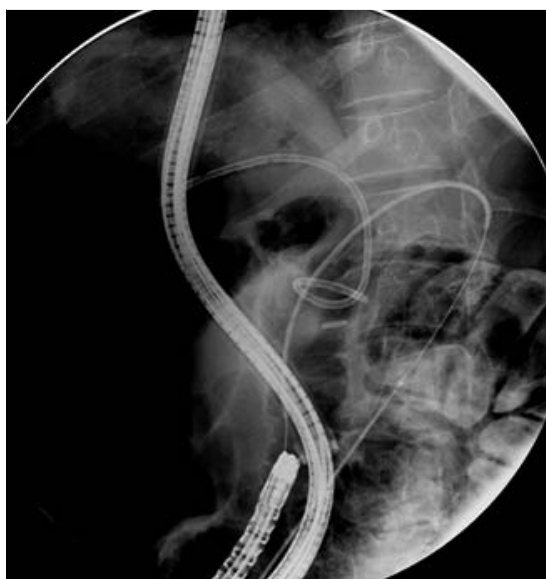

Fig. 4 Endoscopic placement of a 7-Fr plastic biliary stent into the hepaticojejunostomy, over the wire, excluding the bile duct laceration.

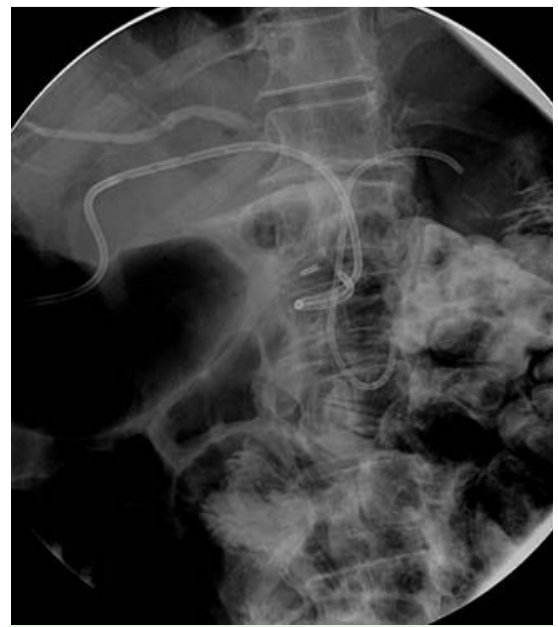

Fig. 5 Final fluoroscopic image showing the percutaneous and endoscopic biliary stents.

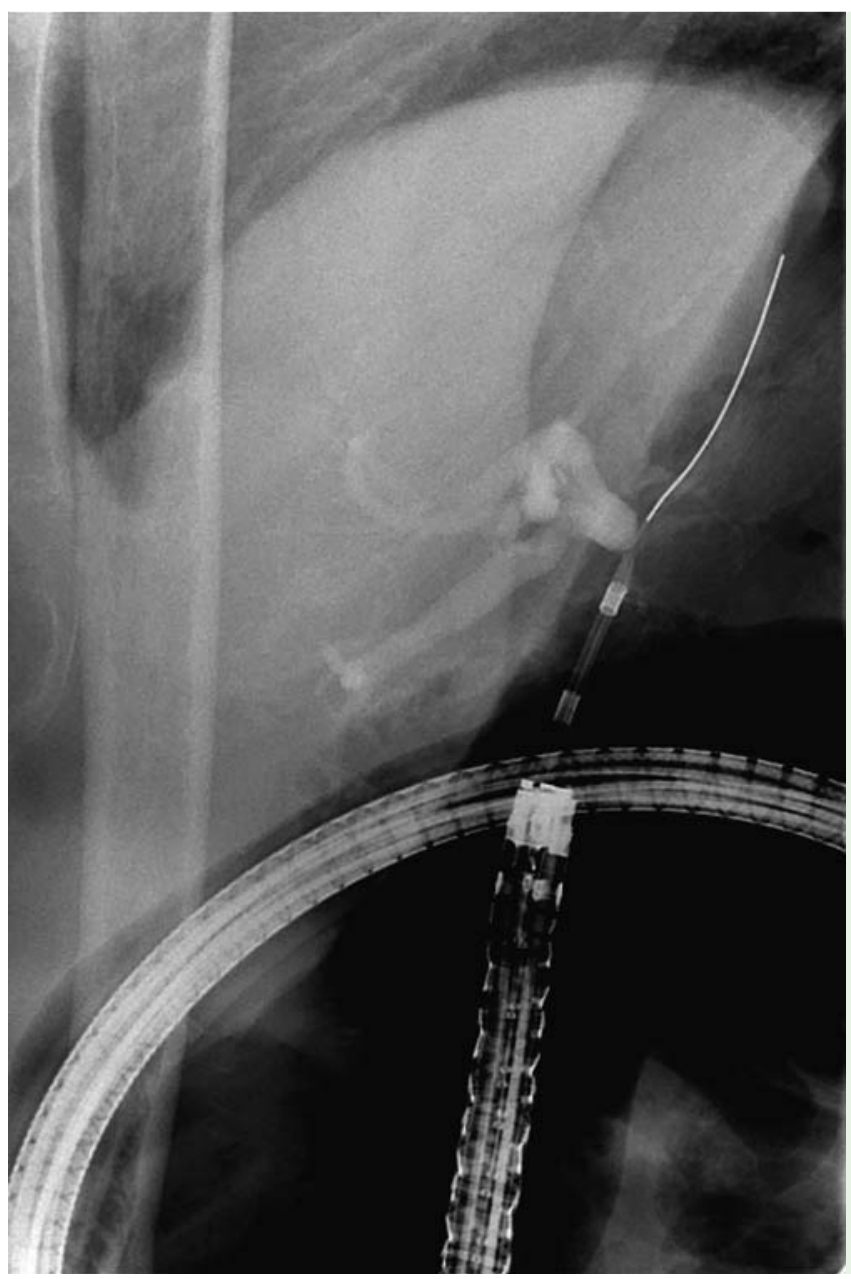

Fig. 6 Cholangiography revealed no leakage or anastomotic stricture after stent removal.

useful method of engaging in biliary endotherapy [1]. In our patient, the use of a combined percutaneous and endoscopic rendezvous technique made it possible to place a biliary stent, establishing biliary continuity and healing an existing biliary duct injury. This procedure, useful for standard ERCP [2], has seldom been described for ERCP by means of balloon- assisted enteroscopy [3-5]. To our knowledge, we present the first description of performance of a rendezvous technique by means of SBE to repair an iatrogenic biliary duct injury. This case also illustrates the gradual improvement of endoscopic biliary interventions in patients with surgically altered anatomy.
Endoscopy_UCTN_Code_CPL_1AM_2AZ

Competing interests: None

\section{Teresa Pinto-Pais ${ }^{1}$, Rolando Pinho ${ }^{1}$, Luísa Proença ${ }^{1}$, Carlos Fernandes ${ }^{1}$, lolanda Ribeiro ${ }^{1}$, Tiago Pereira², José Fraga ${ }^{1}$, João Carvalho ${ }^{1}$}

\section{${ }^{1}$ Department of Gastroenterology and} Hepatology, Centro Hospitalar de Gaia/ Espinho, Gaia, Portugal

2 Department of Radiology, Centro Hospitalar de Gaia/Espinho, Gaia, Portugal

\section{References}

1 Saleem A, Baron TH, Gostout CJ et al. Endoscopic retrograde cholangiopancreatography using a single-balloon enteroscope in patients with altered Roux-en-Y anatomy. Endoscopy 2010; 42: 656-660

2 Nasr JY, Hashash JG, Orons $P$ et al. Rendezvous procedure for the treatment of bile leaks and injury following segmental hepatectomy. Dig Liver Dis 2013; 45: 433 - 436

3 Mönkemüller K, McGuire B, Wilcox CM et al. Percutaneous balloon dilation and placement of endoscopic biliary stent by using the double-balloon enteroscopy ERCP rendezvous technique. Gastrointest Endosc 2013; 78: 383-385

4 Mönkemüller K, Popa D, McGuire B et al Double-balloon enteroscopy-ERCP rendezvous technique. Endoscopy 2013; 45 (Suppl. 02): E333 - 334 [Epub 2013 Oct 22]

5 Itoi $T$, Ishii $K$, Sofuni $A$ et al. Single balloon enteroscopy-assisted ERCP using rendezvous technique for sharp angulation of Roux-en-Y limb in a patient with bile duct stones. Diagn Ther Endosc 2009, doi: 10.1155/2009/154084 [Epub 2010 Feb 14]

Bibliography

DOI http://dx.doi.org/

10.1055/s-0034-1365431

Endoscopy 2014; 46: E506-E507

(C) Georg Thieme Verlag KG

Stuttgart · New York

ISSN 0013-726X

\section{Corresponding author}

\section{Teresa Pinto-Pais, MD}

Department of Gastroenterology and Hepatology Centro Hospitalar de Gaia/Espinho

Rua Conceicao Fernandes

Vila Nova de Gaia 4434-502 Portugal

Fax: +351-227865100

teresapintopais@gmail.com 